\title{
Nav1.3 Sodium Channels: Rapid Repriming and Slow Closed-State Inactivation Display Quantitative Differences after Expression in a Mammalian Cell Line and in Spinal Sensory Neurons
}

\author{
Theodore R. Cummins, Fabio Aglieco, Mathurkrisnan Renganathan, Raimund I. Herzog, \\ Sulayman D. Dib-Hajj, and Stephen G. Waxman
}

Department of Neurology and Paralyzed Veterans of America/Eastern Paralyzed Veterans Association Neuroscience Research Center, Yale Medical School, New Haven, Connecticut 06510, and Rehabilitation Research Center, Veterans Connecticut Healthcare Center, West Haven, Connecticut 06516

\begin{abstract}
Although rat brain Nav1.3 voltage-gated sodium channels have been expressed and studied in Xenopus oocytes, these channels have not been studied after their expression in mammalian cells. We characterized the properties of the rat brain Nav1.3 sodium channels expressed in human embryonic kidney (HEK) 293 cells. Nav1.3 channels generated fast-activating and fastinactivating currents. Recovery from inactivation was relatively rapid at negative potentials $(<-80 \mathrm{mV}$ ) but was slow at more positive potentials. Development of closed-state inactivation was slow, and, as predicted on this basis, Nav1.3 channels generated large ramp currents in response to slow depolarizations. Coexpression of $\beta 3$ subunits had small but significant effects on the kinetic and voltage-dependent properties of Nav1.3 currents in HEK 293 cells, but coexpression of $\beta 1$ and $\beta 2$ subunits had little or no effect on Nav1.3 properties. Nav1.3 channels, mutated to be tetrodotoxin-resistant (TTX-R), were expressed in SNS-null dorsal root ganglion (DRG) neurons via
\end{abstract}

biolistics and were compared with the same construct expressed in HEK 293 cells. The voltage dependence of steadystate inactivation was $\sim 7 \mathrm{mV}$ more depolarized in SNS-null DRG neurons, demonstrating the importance of background cell type in determining physiological properties. Moreover, consistent with the idea that cellular factors can modulate the properties of Nav1.3, the repriming kinetics were twofold faster in the neurons than in the HEK 293 cells. The rapid repriming of Nav1.3 suggests that it contributes to the acceleration of repriming of TTX-sensitive (TTX-S) sodium currents that are seen after peripheral axotomy of DRG neurons. The relatively rapid recovery from inactivation and the slow closed-state inactivation kinetics of Nav1.3 channels suggest that neurons expressing Nav1.3 may exhibit a reduced threshold and/or a relatively high frequency of firing.

Key words: ion channel; $\beta$-subunits; spinal sensory neurons; biolistics; nerve injury; ramp current
Voltage-gated sodium channels play a critical role in excitable cells. Sodium channels underlie the rapid action potentials that are characteristic of neurons and muscle cells and may contribute to subthreshold currents that modulate excitability. At least nine distinct voltage-gated sodium channels have been cloned from mammals (Black and Waxman, 1996; Goldin et al., 2000), and mRNA for almost all of these different channels is found in neurons. Many of these channels have specific developmental, tissue, or cellular distributions. Expression of recombinant channels in Xenopus oocytes and mammalian cells indicates that the different channels also can have distinct kinetic and voltagedependent properties. For example, Smith and Goldin (1998) have shown that, whereas Nav1.1 and Nav1.2 channels both encode fast sodium currents, the voltage dependence of activation and of steady-state inactivation is significantly more positive for the Nav1.1 channels. Cummins et al. (1998) showed that, whereas

\footnotetext{
Received Feb. 16, 2001; revised May 3, 2001; accepted May 31, 2001.

This work was supported in part by grants from the National Multiple Sclerosis Society and the Medical Research Service and Rehabilitation Research Service, Department of Veterans Affairs (S.G.W.). We thank the Eastern Paralyzed Veterans Association and the Paralyzed Veterans of America for support. We also thank W. Hormuzdiar and B. Toftness for excellent technical support and Dr. A. L. Goldin for generously providing the Nav1.3-pBS-SK ${ }^{-}$plasmid.

Correspondence should be addressed to Dr. Stephen G. Waxman, Department of Neurology, Yale University School of Medicine, 333 Cedar Street, P.O. Box 208018, New Haven, CT 06520-8018. E-mail: Stephen.Waxman@Yale.Edu.

Copyright (ㄷ) 2001 Society for Neuroscience $0270-6474 / 01 / 215952-10 \$ 15.00 / 0$
}

Nav1.7 and Nav1.4 channels expressed in human embryonic kidney (HEK) 293 cells have similar voltage-dependent properties, Nav1.7 channels display much slower closed-state inactivation kinetics than Nav1.4 channels. This difference in closed-state inactivation endows Nav1.7 channels with the ability to generate ramp currents in response to slow depolarizations, a property that may permit them to play an important role in boosting subthreshold stimuli. Thus differences in the kinetic and voltage-dependent properties of voltage-gated sodium channels may be an important determinant of the integrative and firing properties of neurons.

Nav1.3 neuronal channels are expressed primarily at early stages during development and are almost undetectable in the normal adult nervous system (Felts et al., 1997). However, Nav1.3 channels are reexpressed in adult neurons after some types of injury, such as axotomy (Waxman et al., 1994) and kainateinduced seizures (Gastaldi et al., 1997). The levels of Nav1.3 mRNA and protein are increased in sensory neurons after transection of their peripheral, but not their central, axons (Black et al., 1999). The increase in Nav1.3 protein and mRNA levels after peripheral axotomy is paralleled by a switch from tetrodotoxinsensitive (TTX-S) current with slow recovery from inactivation to TTX-S current that recovers fourfold faster in small dorsal root ganglion (DRG) neurons (Cummins and Waxman, 1997), a change that is expected to increase the ability of these neurons to sustain repetitive firing (see, for example, Chahine et al., 1994; Yang et al., 1994). These results suggest that the functional 
properties of Nav1.3 sodium channels may play an important role in the DRG neuron hyperexcitability that can occur after nerve injury. Therefore, we were interested in determining the voltagedependent and kinetic properties of Nav1.3 channels expressed in mammalian cells.

In this study we first examined the electrophysiological properties of Nav1.3 channels expressed alone and with $\beta$-subunits in a mammalian cell line, HEK 293 cells. Because there are data suggesting that the properties of sodium channels depend on the type of cell in which they are expressed, we also wished to express Nav1.3 channels in DRG neurons. To facilitate identification of the currents produced by these channels, we created a tetrodotoxin-resistant (TTX-R) Nav1.3 construct and used biolistics to express it in SNS-null DRG neurons in which other TTX-R sodium currents are not expressed. Our results show that the physiological properties of Nav1.3 channels depend on the cell type in which they are expressed and indicate that Nav1.3 channels contribute to rapidly repriming TTX-S current in axotomized DRG neurons.

\section{MATERIALS AND METHODS}

Construction of mammalian expression vectors encoding neuronal rat Nav1.3 (rNav1.3) channel. The insert of rNav1.3 was moved from the bacterial expression pBluescript SK ${ }^{-}\left(\mathrm{pBS}^{-\mathrm{SK}^{-}}\right.$) plasmid (Joho et al., 1990) into a mammalian expression vector pcDNA3.1 (Invitrogen, San Diego, CA) that was modified to render it a low copy number plasmid (Klugbauer et al., 1995). The open reading frame of rNav1.3 was removed from the bacterial expression plasmid by a SalI/NotI double digest. The SalI end was polished to produce a blunt end, and the fragment was cloned into the modified pcDNA3 vector cut with HindIII and NotI. The HindIII site of the vector was polished to receive the polished SalI site of the insert. The insert was sequenced to confirm its integrity. When compared with the published sequence (Kayano et al., 1988), multiple nucleotide substitutions were detected as described previously (Joho et al., 1990). The construct was modified later to delete the 3 -untranslated region downstream from the translation termination codon TAA.

A PCR-based mutagenesis and cloning method (Horton et al., 1993) was used to replace the amino acid tyrosine at position 384 with serine (Y384S) to make this channel resistant to TTX. One wild-type primer pair (T7 in the vector and R1) and one mutagenic pair (M1 and M2) were used to introduce the Y384S substitution. The T7 primer, upstream of the cloning site in the vector, was used as the forward wild-type primer. The wild-type reverse primer R1 (5'-CGACTTGGGAAACCTGTCTCCATCG-3') corresponds to nucleotides 1991-1967. Forward mutagenic primer M1 (5'-ACTCAGGACTCCTGGGAGAATCTTTAC-3'; the A-to-C substitution, in boldface type, changes the tyrosine TAC codon to serine codon TCC) corresponds to nucleotides 1554-1580. Reverse mutagenic primer M2 (5'-ATTCTCCCAGGAGTCCTGAGTCATGAG-3'; a T-to-G substitution, in boldface type, complements the change in the mutagenic forward primer) corresponds to nucleotides 1574-1548. PCR was performed as described previously (Dib-Hajj et al., 1997). The final PCR product carrying the Y384S substitution was cut with the restriction enzymes NheI (in the vector) and SacII in the insert; then the fragment was used to replace the corresponding fragment from the wild-type insert. The mutation was confirmed by sequencing the whole Nav1.3 insert. Sequencing of the mutant insert revealed two additional mutations in the S5-S6 linker upstream of the Y384 position: a glycine-to-arginine change at position 349 (G349R) and a conservative change of isoleucine to leucine at position 351 (I351L). These changes are not expected to affect the TTX phenotype of the channel.

Construction of mammalian expression vectors encoding human $\beta 2$ and rat $\beta 3$ subunits. A PCR fragment encoding the sodium channel $\beta 2$ subunit (Eubanks et al., 1997) was amplified from a human DRG template by using a forward primer (5'-CTGAAAATGCACAGAGATGCCTGG$3^{\prime}$, which corresponds to nucleotides 167-190) and reverse primer (5'CACTACTTGGCGCCATCATCCG-3', which corresponds to nucleotides 822-801). The PCR product first was cloned into pGEM-T (Promega, Madison, WI) and later moved as an EcoRI insert into pcDNA3.1 (Invitrogen) for expression in mammalian cells. The sequence of the insert matched the published sequence except for a T-to-C nucle- otide substitution that replaced serine at position 44 of the polypeptide by a proline (S44P). It is not clear whether this change was introduced by the amplification/cloning process or whether it reflects a naturally occurring polymorphism.

A PCR fragment encoding the sodium channel $\beta 3$ subunit (Morgan et al., 2000) was amplified from a rat DRG template with a forward primer (5'-AAGATGCCTGCCTTCAACAGATTGCTTC-3', which corresponds to nucleotides 3-30) and reverse primer (5'-CACCACATTATTCCTCCACAGGTAC-3', which corresponds to nucleotides 670-647). The PCR product was cloned into pTarget (Promega). The sequence of the insert matched the published sequence. The cloning of the $\beta 1$ subunit construct has been described previously (Tong et al., 1993; Bendahhou et al., 1995).

Transfection of HEK 293 cells. Transfections of HEK 293 cells were performed via the calcium phosphate precipitation technique as described previously (Cummins et al., 1998). Green fluorescent protein (GFP) was used to select for transfected cells, which subsequently were tested for channel expression by whole-cell patch-clamp recording techniques.

Axotomized DRG neurons. Adult rats were anesthetized with sodium pentobarbital $(60 \mathrm{mg} / \mathrm{kg}$ of body weight), and the right sciatic nerves were exposed at the mid-thigh level, ligated with 4-0 silk sutures, and transected; the proximal stumps were placed in silicon cuffs to prevent regeneration (Waxman et al., 1994). Hydroxystilbamine methanesulfonate ( $4 \% \mathrm{w} / \mathrm{v}$; Molecular Probes, Eugene, OR), the active component of Fluorogold and a retrogradely transported fluorescent label, was placed in all cuffs before insertion of the nerve stump. The fluorescent label identified neurons that gave rise to axons that were transected.

Culture of DRG neurons. Axotomized DRG cells were studied after short-term culture (12-24 hr). The short-term culture provided cells with truncated axonal processes that can be voltage clamped readily and reliably and also allowed the cells sufficient time to adhere to the glass coverslip. Adult rat DRG neurons maintained in vitro for $24 \mathrm{hr}$ display a profile of sodium channel mRNA expression similar to that for DRG neurons in situ, indicating that short-term culture does not alter the expression of sodium channel mRNAs substantially in these cells (Black et al., 1996). Briefly, the L4 and L5 DRG ganglia were harvested from adult male Sprague Dawley rats. The DRG were treated with collagenase A $(1 \mathrm{mg} / \mathrm{ml})$ for $25 \mathrm{~min}$ and collagenase $\mathrm{D}(1 \mathrm{mg} / \mathrm{ml})$ and papain $(30$ $\mathrm{U} / \mathrm{ml}$ ) for $25 \mathrm{~min}$, dissociated in DMEM and Ham's F12 medium supplemented with $10 \%$ fetal bovine serum, and plated on glass coverslips. Recordings were made within $24 \mathrm{hr}$ of dissociation.

Biolistic transfection of SNS-null DRG neurons. The Helios Gene Gun System (Bio-Rad Laboratories, Hercules, CA) was used for the biolistic transfection of neurons with DNA-coated gold particles. In the presence of a $0.05 \mathrm{M}$ solution of the polyanion spermidine, $10 \mu \mathrm{g}$ of Nav1.3TTX-R DNA was mixed with $5 \mu \mathrm{g}$ of GFP DNA and coprecipitated onto $1 \mu \mathrm{m}$ gold particles with $\mathrm{CaCl}_{2}$. The DNA gold suspension was washed twice in $100 \%$ ethanol, resuspended in $0.05 \%$ polyvinylpyrrolidone in ethanol, and used for coating the inner wall of 10 inches of Tefzel tubing (Bio-Rad Laboratories). The tubing was dried by using ultrapure nitrogen and was cut into $\sim 20$ cartridges for the Helios Gene Gun. This process resulted in a density of $1 \mathrm{mg}$ of gold particles per shot and 0.75 $\mu \mathrm{g}$ of total DNA per cartridge.

DRG neurons were isolated from SNS-null mice (Akopian et al., 1999) by the same procedure described for the axotomized rat DRG neurons, with the exception that the SNS-null neurons were kept under standard tissue culture conditions for 3-5 d before biolistic transfections. We have shown previously that SNS-null DRG neurons express persistent TTX-R sodium currents (Cummins et al., 1999), but these currents are typically $<1 \mathrm{nA}$ after several days in culture and run down quickly ( $<10 \mathrm{~min}$ ) in whole-cell recording configuration; therefore, these persistent TTX-R currents are not significant under the culture and recording conditions that were used in the present study. Just before biolistic transfection the culture medium was removed from the Petri dish. The gene gun was held $1 \mathrm{~cm}$ above the cells, and a pressure of $\sim 120$ psi was used to deliver the gold particles to the cells. A $70 \mu$ m nylon mesh (Small Parts, Miami, FL) was placed just in front of the Helios Gene Gun barrel liner to achieve a more uniform distribution of gold particles (Wellmann et al., 1999).

Within $24 \mathrm{hr}$ the cells usually showed expression of GFP, indicating a successful biolistic transfection. Electrophysiological studies were conducted 18-48 hr after transfection, and most of the cells that expressed GFP also expressed fast-inactivating TTX-R sodium currents. Because these currents are not observed in untransfected SNS-null neurons or SNS-null neurons transfected with just GFP-coated gold particles, this 
confirmed that most of the cells that expressed GFP also had been cotransfected successfully with the Nav1.3-TTX-R channel.

Whole-cell patch-clamp recordings. Whole-cell patch-clamp recordings were conducted at room temperature $\left(\sim 21^{\circ} \mathrm{C}\right)$ with an EPC-9 amplifier. Data were acquired on a Windows-based Pentium III computer with the Pulse program (v 8.1, HEKA Electronics, Lambrecht, Germany). Firepolished electrodes $(0.8-1.5 \mathrm{M} \Omega)$ were fabricated from $1.7 \mathrm{~mm}$ capillary glass, using a Sutter P-97 puller (Novato, CA). To minimize space-clamp problems, we selected only isolated cells with a soma diameter of $<25$ $\mu \mathrm{m}$ for recording. Cells were not considered for analysis if the initial seal resistance was $<2 \mathrm{G} \Omega$, if they had high leakage currents (holding current $>0.1 \mathrm{nA}$ at $-80 \mathrm{mV}$ for HEK 293 cells; $>0.5 \mathrm{nA}$ for DRG neurons), or an access resistance $>4 \mathrm{M} \Omega$. The average access resistance was $1.7 \pm 0.6$ $\mathrm{M} \Omega($ mean $\pm \mathrm{SD})$. Voltage errors were minimized by using $80-90 \%$ series resistance compensation, and the capacitance artifact was canceled by using the computer-controlled circuitry of the patch-clamp amplifier. Linear leak subtraction, based on resistance estimates from four to five hyperpolarizing pulses applied before the depolarizing test potential, was used for all voltage-clamp recordings. Membrane currents usually were filtered at $2.5 \mathrm{kHz}$ and sampled at $10 \mathrm{kHz}$. The pipette solution contained (in mM) $140 \mathrm{CsF}, 1$ EGTA, $10 \mathrm{NaCl}$, and 10 HEPES, pH 7.3. The standard bathing solution was (in $\mathrm{mM}$ ) $140 \mathrm{NaCl}, 3 \mathrm{KCl}, 1 \mathrm{MgCl}_{2}, 1$ $\mathrm{CaCl}_{2}$, and $10 \mathrm{HEPES}, \mathrm{pH}$ 7.3. The liquid junction potential for these solutions was $<8 \mathrm{mV}$; data were not corrected to account for this offset. The osmolarity of all solutions was adjusted to $310 \mathrm{mOsm}$ (Wescor 5500 osmometer, Logan, UT). The offset potential was zeroed before the cells were patched.

Data analysis. Data were analyzed with the Pulsefit (HEKA Electronics) and Origin (Microcal Software, Northampton, MA) software programs. Unless otherwise noted, statistical significance was determined by $p<0.05$, using an unpaired Student's $t$ test. Results are presented as mean \pm SEM, and error bars in the figures represent SE. The curves in the figures are drawn to guide the eye unless otherwise noted. Time course data were fit with single exponential functions.

\section{RESULTS}

\section{Sodium current activation}

We compared the kinetic and voltage-dependent properties of TTX-S sodium currents from axotomized DRG neurons in which Nav1.3 sodium channel mRNA and protein are known to be upregulated (Dib-Hajj et al., 1996; Black et al., 1999) with the currents from HEK 293 cells transfected with recombinant rat brain Nav1.3 sodium channels. Fast-inactivating TTX-S sodium currents were observed in HEK 293 cells transfected with Nav1.3 channels (Fig. 1A), and these currents appear to be similar to those recorded from axotomized DRG neurons (Fig. 1B). The threshold and voltage dependence of activation for the peak sodium current were similar for Nav1.3 currents and for TTX-S sodium currents in axotomized DRG neurons (Fig. 1C). The midpoint of activation was $-25.5 \pm 1.6 \mathrm{mV}$ (mean $\pm \mathrm{SEM}, n=$ 24) for Nav1.3 currents and $-29.1 \pm 2.0 \mathrm{mV}(n=17)$ for axotomized DRG currents. In HEK 293 cells, Nav1.3 currents have slightly slower kinetics compared with sodium currents in axotomized DRG neurons (Fig. 1D). However, this simply may reflect a shifted voltage dependence of inactivation. Both the macroscopic open-state inactivation time constant versus voltage curve (Fig. $1 E$ ) and the steady-state inactivation curve (Fig. $1 F$ ) are shifted by approximately $+10 \mathrm{mV}$ for Nav1.3 channels in HEK 293 cells compared with TTX-S sodium currents in axotomized DRG neurons. The midpoint of steady-state inactivation was $-64.9 \pm 1.5 \mathrm{mV}$ (mean $\pm \mathrm{SEM}, n=25$ ) for Nav1.3 currents and $-72.2 \pm 1.3 \mathrm{mV}(n=19)$ for axotomized DRG currents.

\section{Development of closed-state inactivation}

Recently, we demonstrated that Nav1.7 channels exhibit fivefold slower closed-state inactivation than Nav1.4 channels in HEK 293 cells, and we suggested that differences in closed-state inactivation might be an important determinant for the generation of
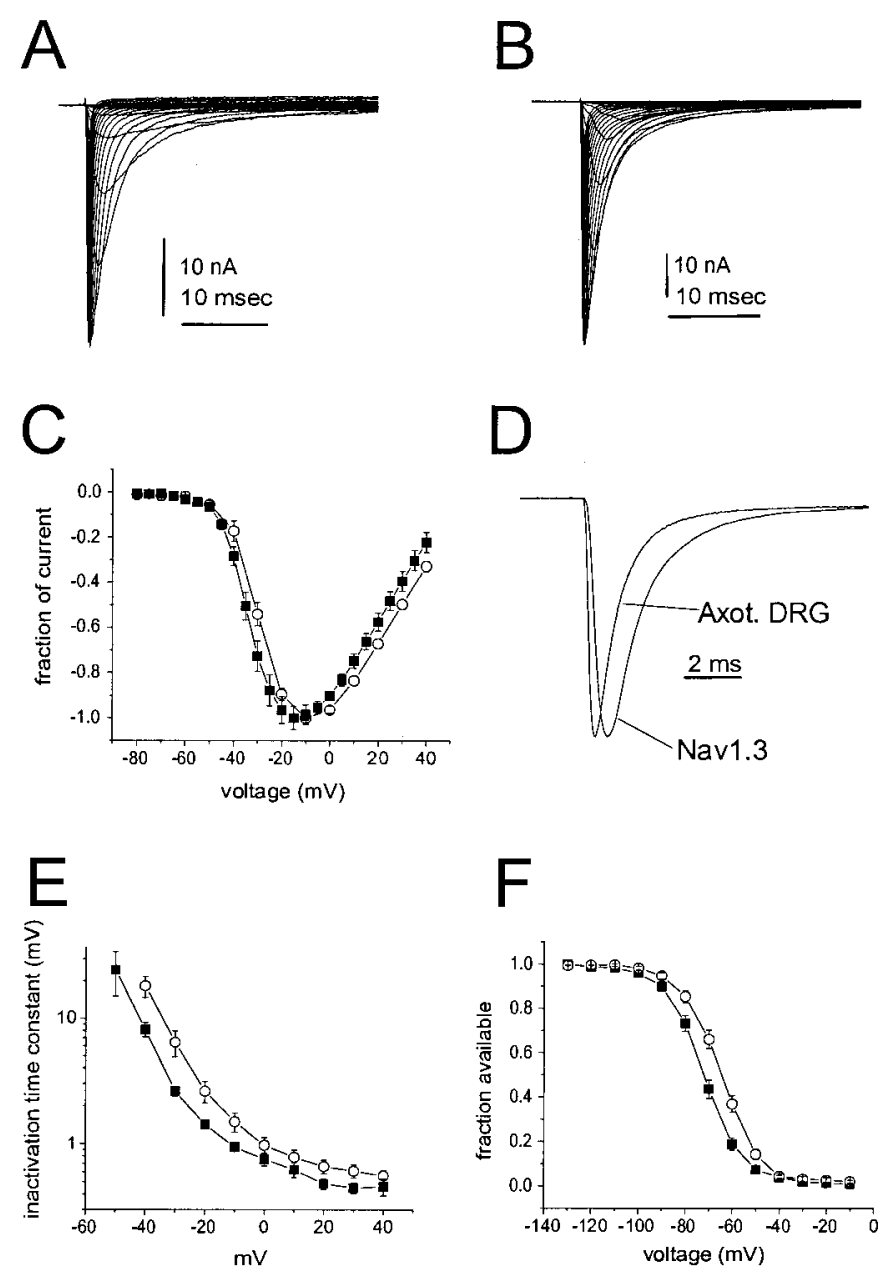

Figure 1. Comparison of Nav1.3 currents in HEK 293 cells and TTX-S currents in axotomized DRG neurons. $A$, Family of traces from representative HEK 293 cells expressing rat Nav1.3 channels. B, Family of sodium current traces from representative axotomized rat small DRG neuron. The currents were elicited by $40 \mathrm{msec}$ test pulses to various potentials from -80 to $+40 \mathrm{mV}$. Cells were held at $-120 \mathrm{mV}$. $C$, Normalized peak current-voltage relationship for Nav1.3 channels (open circles; $n=24$ ) and axotomized DRG TTX-S sodium currents ( filled squares; $n=17)$. $D$, Representative currents from whole-cell recordings of an HEK 293 cell expressing Nav1.3 channels and an axotomized small DRG neuron from rat. Currents were elicited by a step depolarization to $-10 \mathrm{mV}$ from a holding potential of $-120 \mathrm{mV}$ and were scaled for comparison. The Nav1.3 current displays slower kinetics. $E$, Inactivation kinetics as a function of voltage. The macroscopic decay time constant is greater for Nav1.3 currents in HEK 293 cells (open circles; $n=9$ ) than for axotomized DRG TTX-S sodium currents ( filled squares; $n=11$ ) at each voltage. Time constants were estimated from single exponential fits to the decay phase of currents elicited by $100 \mathrm{msec}$ step depolarizations to the indicated potential. $F$, Comparison of Nav1.3 (open circles; $n=13$ ) and axotomized DRG TTX-S sodium current ( filled squares; $n=12$ ) steadystate inactivation. Steady-state inactivation was estimated by measuring the peak current amplitude elicited by $20 \mathrm{msec}$ test pulses to $-10 \mathrm{mV}$ after $500 \mathrm{msec}$ prepulses to potentials over the range of -130 to $-10 \mathrm{mV}$. Current is plotted as a fraction of the maximum peak current.

threshold ramp currents (Cummins et al., 1998). Therefore, we compared the development of inactivation kinetics of Nav1.3 channels in HEK 293 cells with that of TTX-S sodium currents from axotomized small DRG neurons. At $-70 \mathrm{mV}$ the development of inactivation was slow for heterologously expressed Nav1.3 channels (Fig. 2A) and for TTX-S sodium currents from axotomized small DRG neurons (Fig. 2B). The time constant for 
A

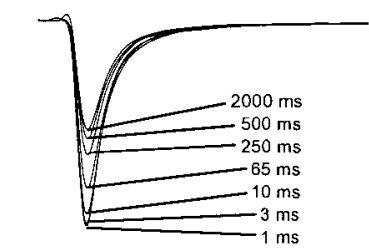

B

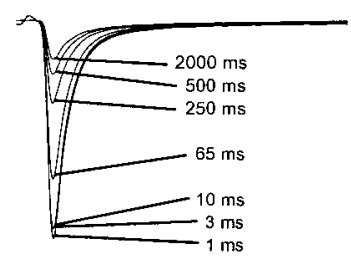

C

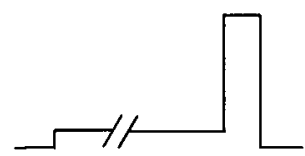

$\Delta \mathrm{t}, \mathrm{Vdev}$

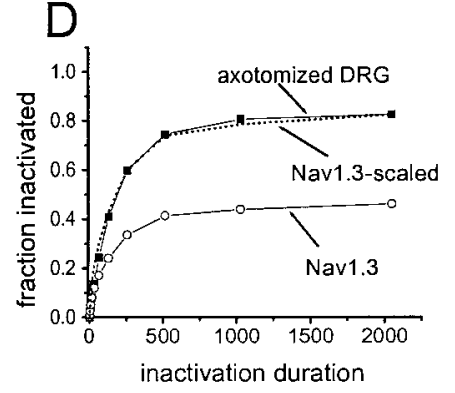

Figure 2. Development of closed-state inactivation is similar for Nav1.3 channels expressed in HEK 293 cells and TTX-S sodium currents in axotomized DRG neurons. $A, B$, Family of current traces from HEK 293 cells expressing Nav1.3 channels $(A)$ and from axotomized DRG neurons $(B)$ showing the rate of development of inactivation at $-70 \mathrm{mV}$. $C$, The standard development of inactivation voltage protocol. From a holding potential of $-120 \mathrm{mV}$ the cells were prepulsed to $-70 \mathrm{mV}\left(V_{\mathrm{dev}}\right)$ for increasing durations $(\Delta t)$ and then stepped to $-20 \mathrm{mV}$ to determine the fraction of current that was inactivated during the prepulse. The duration of the inactivation prepulse for each data trace in $A$ and $B$ is indicated. $D$, Time course for the development of inactivation for the peak current. Inactivation develops at the same rate at $-70 \mathrm{mV}$ for Nav1.3 channels expressed in HEK 293 cells (open circles) and TTX-S sodium currents in axotomized DRG neurons (filled squares). The fraction of channels that inactivates at $-70 \mathrm{mV}$ is lower for the Nav1.3 currents in HEK 293 cells; therefore, for comparison the time course for the Nav1.3 currents is shown scaled to that of the time course for TTX-S sodium currents in axotomized DRG neurons (dotted curve).

development of inactivation was $\sim 150 \mathrm{msec}$ for both heterologously expressed Nav1.3 channels and TTX-S sodium currents from axotomized small DRG neurons at $-70 \mathrm{mV}$ (Fig. $2 D$ ).

The time constant for development of inactivation was estimated at voltages ranging from -90 to $-40 \mathrm{mV}$ and was relatively large throughout this voltage range for both heterologously expressed Nav1.3 channels and TTX-S sodium currents from axotomized small DRG neurons (Fig. $3 A$ ). On the basis of these estimates we predicted that the sodium currents in these two cell types would generate inward currents during slow ramp depolarizations. Indeed, large currents were evoked by slow ramps $(-100$ to $+40 \mathrm{mV}$ over $600 \mathrm{msec}$ ) in HEK 293 cells expressing Nav1.3 channels (Fig. 3B), and these ramps elicited TTX-S sodium currents from axotomized small DRG neurons (Fig. 3C). In $11 \mathrm{HEK}$ 293 cells expressing Nav1.3 channels, the ramp currents elicited by $600 \mathrm{msec}$ ramp depolarizations averaged $7.0 \pm 0.9 \%$ of the peak current amplitude. By contrast, the ramp currents in axotomized small DRG neurons were smaller, averaging $4.1 \pm 0.5 \%$ of the peak TTX-S current amplitude $(n=8)$. The ramp currents generated by Nav1.3 in HEK 293 cells activated $\sim 10 \mathrm{mV}$ more negatively than the ramp currents in axotomized small DRG neurons (Fig. 3D).

\section{Recovery from inactivation}

In small DRG neurons the increase in Nav1.3 channel mRNA expression after axotomy of the sciatic nerve is paralleled by a
A
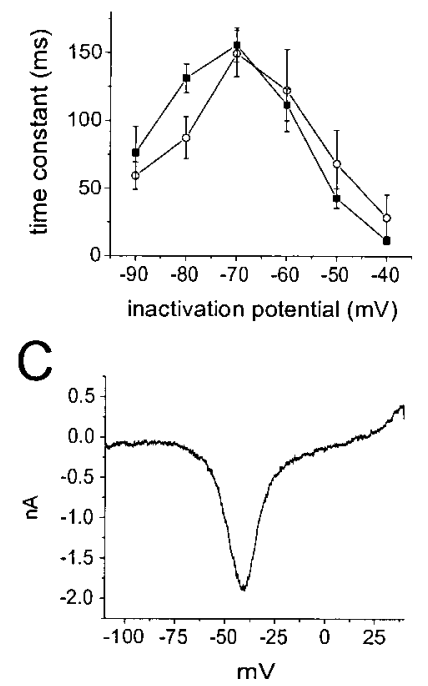

B
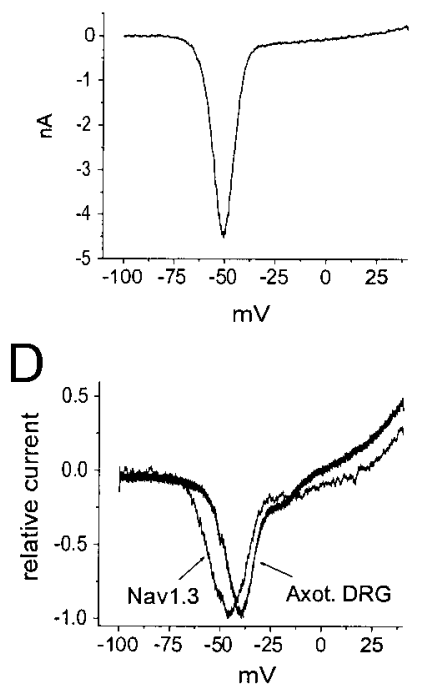

Figure 3. Nav1.3 currents exhibit slow closed-state inactivation and generate large ramp currents. $A$, The time constants for the development of inactivation are plotted as a function of voltage. Time constants were estimated from single exponential fits to time courses measured with the protocol shown in Figure $2 C$ for HEK 293 cells expressing Nav1.3 channels (open circles; $n=8$ ) and TTX-S sodium currents in axotomized DRG neurons ( filled squares; $n=8$ ). The inactivation voltage $\left(V_{\mathrm{dev}}\right)$ was varied from -90 to $-40 \mathrm{mV}$. $B$, Current elicited in a HEK 293 cell expressing Nav1.3 channels by a $600 \mathrm{msec}$ ramp depolarization from -100 to $+40 \mathrm{mV}$. $C$, Current elicited in a axotomized rat small DRG neurons by a $600 \mathrm{msec}$ ramp depolarization from -100 to $+40 \mathrm{mV}$. D, Comparison of averaged ramp currents from HEK 293 cells expressing Nav1.3 channels $(n=6)$ and axotomized rat small DRG neurons $(n=3)$. Currents were normalized and averaged for a comparison of voltage dependence.

change from TTX-S sodium currents with slow recovery from inactivation to TTX-S sodium currents with more rapid recovery from inactivation in small DRG neurons (Cummins and Waxman, 1997; Black et al., 1999). Therefore, we compared the recovery from inactivation (repriming) kinetics of Nav1.3 channels in HEK 293 cells with that of TTX-S sodium currents from axotomized small DRG neurons. At $-100 \mathrm{mV}$ the repriming rates were similar (Fig. $4 A$ ), but at $-70 \mathrm{mV}$ the Nav1.3 currents in HEK 293 cells reprimed more slowly than sodium currents from axotomized DRG neurons (Fig. $4 B$ ). As Figure $4 D$ shows, the repriming time constants were similar at negative potentials (less than or equal to $-90 \mathrm{mV}$ ) but significantly different between -80 and $-60 \mathrm{mV}$.

\section{Effect of coexpression with $\boldsymbol{\beta}$-subunits}

Neuronal sodium channel $\alpha$-subunits are associated typically with one or more $\beta$-subunits (Isom, 2000), and the expression of sodium channel $\beta$-subunits changes with development (Sashihara et al., 1995) and after nerve injury (Shah et al., 2000). To determine whether sodium channel $\beta$-subunits might alter the properties of Nav1.3 channels, we cotransfected $\beta 1, \beta 2$, and $\beta 3$ subunits with Nav1.3 in HEK 293 cells. Because $\beta 1$ and $\beta 2$ subunits are found to be coexpressed in some neurons, we also coexpressed Nav1.3 with $\beta 1$ and $\beta 2$ subunits $(\beta 1+\beta 2)$. Fast-inactivating sodium currents were observed when the $\beta$-subunits were coexpressed with Nav1.3 (Fig. $5 A-E$ ). The voltage dependence of activation was similar for Nav1.3, Nav1.3+ $\beta 1$, Nav1.3+ $\beta 2$, and Nav1.3 $+\beta 1+\beta 2$ (Fig. $5 F$ ). However, the voltage dependence of 
A

Nav1.3

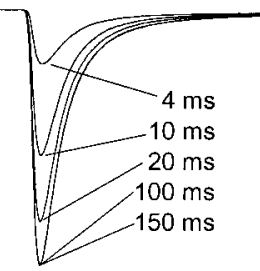

B

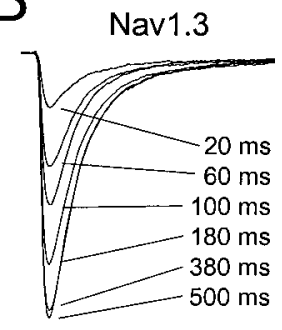

DRG

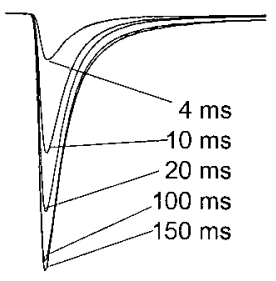

\section{DRG}

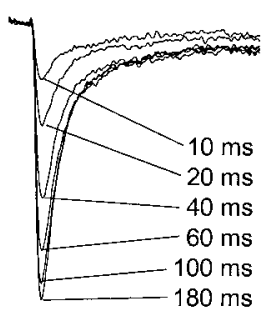

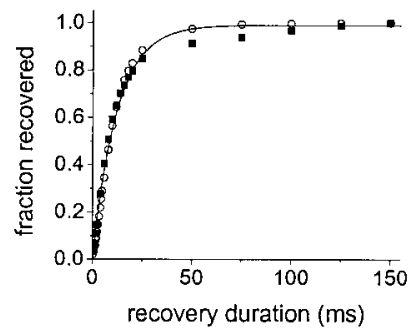

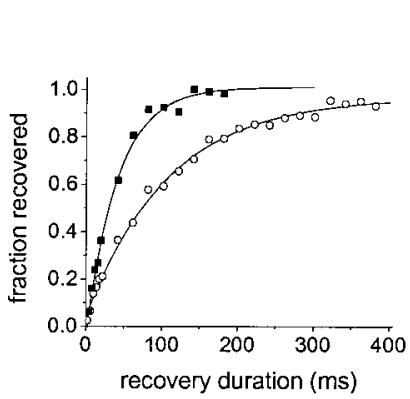

C

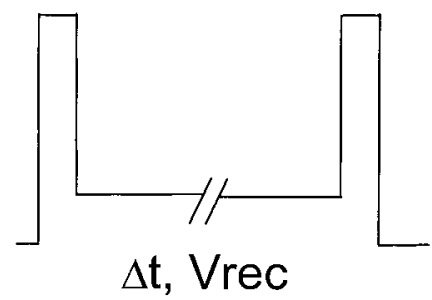

D

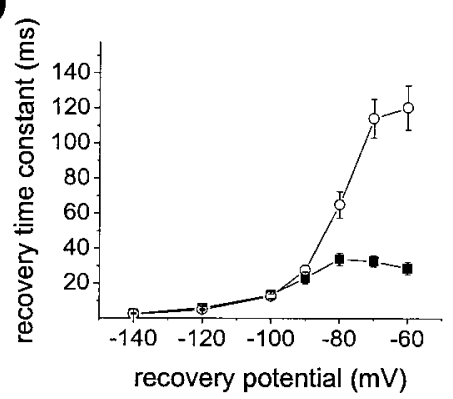

Figure 4. Recovery from inactivation kinetics diverges for Nav1.3 channels in HEK 293 cells and TTX-S currents in axotomized DRG neurons. A, Family of current traces from representative HEK 293 cell expressing Nav1.3 channels and an axotomized DRG neuron showing the rate of recovery from inactivation at $-100 \mathrm{mV}$. The time course for recovery from inactivation of peak currents at $-100 \mathrm{mV}$ is shown at right. Recovery is similar for Nav1.3 channels expressed in HEK 293 cells (open circles) and TTX-S sodium currents in axotomized DRG neurons ( filled squares). B, Family of current traces from HEK 293 cell expressing Nav1.3 channels or axotomized DRG neuron showing the rate of recovery from inactivation at $-70 \mathrm{mV}$. The time course for recovery from inactivation of peak currents at $-70 \mathrm{mV}$ is shown at right. Recovery is slower for Nav1.3 channels expressed in HEK 293 cells (open circles) than for TTX-S sodium currents in axotomized DRG neurons ( filled squares). $C$, The standard recovery from the inactivation voltage protocol is shown. The cells were prepulsed to $-20 \mathrm{mV}$ for $20 \mathrm{msec}$ to inactivate all of the current and then brought back to the recovery potential ( $V_{\text {rec }}$ ) for increasing recovery durations $(\Delta t)$ before the test pulse to $-20 \mathrm{mV}$. The maximum pulse rate was $0.5 \mathrm{~Hz}$. The times indicated for each trace shown in $A$ and $B$ correspond to the recovery duration for that trace. $D$, The time constants for recovery from inactivation are plotted as a function of voltage. Time constants were estimated from single exponential fits to time courses measured at recovery potentials ranging from -140 to $-60 \mathrm{mV}$ with the protocol shown in $C$ for HEK 293 cells expressing Nav1.3 channels (open circles; $n=23$ ) and TTX-S sodium currents in axotomized DRG neurons ( filled squares; $n=17)$.

activation was shifted by $+7 \mathrm{mV}$ for Nav1.3+ $\beta 3$ (Fig. $5 F$ ) compared with Nav1.3, and this shift was significant $(p<0.01)$.

We also examined the effect of $\beta$-subunit coexpression on the voltage dependence of steady-state inactivation (Fig. $6 A$ ). The $\beta 3$ subunit shifted steady-state inactivation for Nav1.3 in the depolarizing direction by $7 \mathrm{mV}(p<0.01)$, and coexpression of both the $\beta 1$ and $\beta 2$ subunits shifted steady-state inactivation by $5 \mathrm{mV}$ $(p<0.05)$. Expression of either the $\beta 1$ or $\beta 2$ subunit did not alter the time constants significantly for macroscopic open-state inactivation, but the Nav1.3 channels coexpressed with the $\beta 3$ subunit showed slower rates of inactivation at test potentials ranging from -40 to $-10 \mathrm{mV}$ (Fig. $6 B$ ). This indicates that the $\beta 3$ subunit has larger effects on the inactivation properties of Nav1.3 channels than the $\beta 1$ or $\beta 2$ subunits.

Because Nav1.3 channels exhibited different repriming kinetics from TTX-S sodium currents in axotomized neurons, we asked whether coexpression of $\beta$-subunits altered repriming kinetics. The time constants for recovery from inactivation were measured in cells coexpressing Nav1.3+ $\beta 1$, Nav1.3+ $\beta 2$, Nav1.3+ $\beta 1+\beta 2$, and Nav1.3+ $\beta 3$ (Fig. $6 C$ ). At $-80 \mathrm{mV}$ the recovery from inactivation was $\sim 50 \%$ faster for Nav1.3+ $\beta 1$ and Nav1.3+ $\beta 3$ than for Nav1.3 expressed alone $(p<0.05)$. However, at -70 and -60 $\mathrm{mV}$, the time constants for recovery from inactivation were still substantially smaller for sodium currents from axotomized DRG neurons (dotted curve) than for Nav1.3 channels coexpressed with $\beta$-subunits (Fig. 6C). Development of closed-state inactivation was not altered significantly by the coexpression of $\beta$-subunits with Nav1.3 channels (Fig. 6D).

\section{Comparison of Nav1.3 channels expressed in HEK and DRG neurons}

Recent data suggest that sodium channel properties can depend on the cell type in which the channel is expressed. For example, Nav1.6 channels appear to underlie resurgent currents in cerebellar Purkinje neurons, but not in hippocampal CA3 neurons (Raman et al., 1997) or cultured spinal neurons (Pan and Beam, 1999). Therefore, we asked whether recombinant Nav1.3 channels had different properties when expressed in HEK 293 cells and DRG neurons. Because it would be difficult to identify wild-type Nav1.3 channels expressed in DRG neurons in the presence of large endogenous TTX-S currents, we created a TTX-R Nav1.3 construct by replacing the tyrosine at position 384 with a serine. These channels were not inhibited by $1 \mu \mathrm{M}$ TTX (data not shown), permitting us to identify the currents produced by recombinant Nav1.3 channels after TTX-S currents were blocked with TTX. When we created the Nav1.3-TTX-R channel, two additional mutations (see Materials and Methods) also were inserted inadvertently into the Nav1.3 construct. Efforts to correct these additional mutations were not successful. The voltage dependence of activation and of steady-state inactivation was $\sim 10$ $\mathrm{mV}$ more depolarized for the Nav1.3-TTX-R channels expressed in HEK 293 cells than for wild-type Nav1.3-TTX-R channels 
A
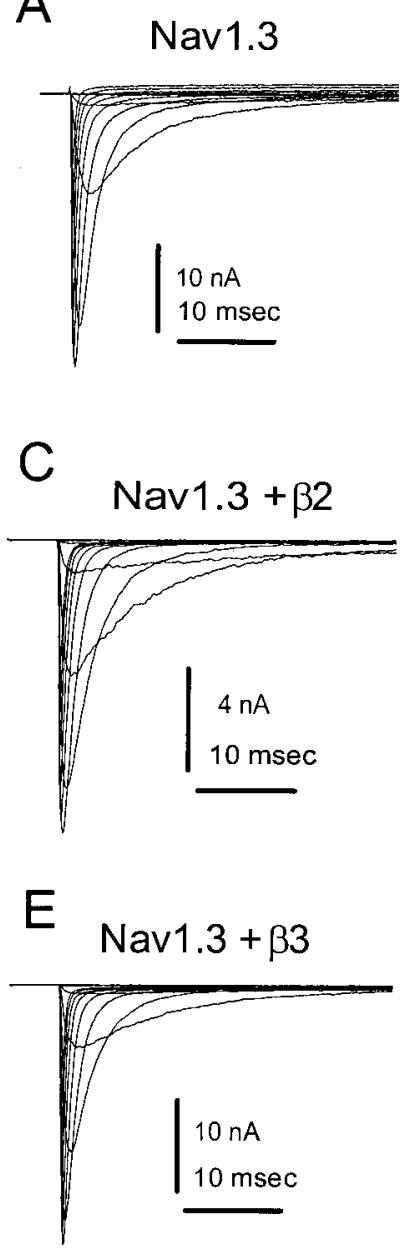
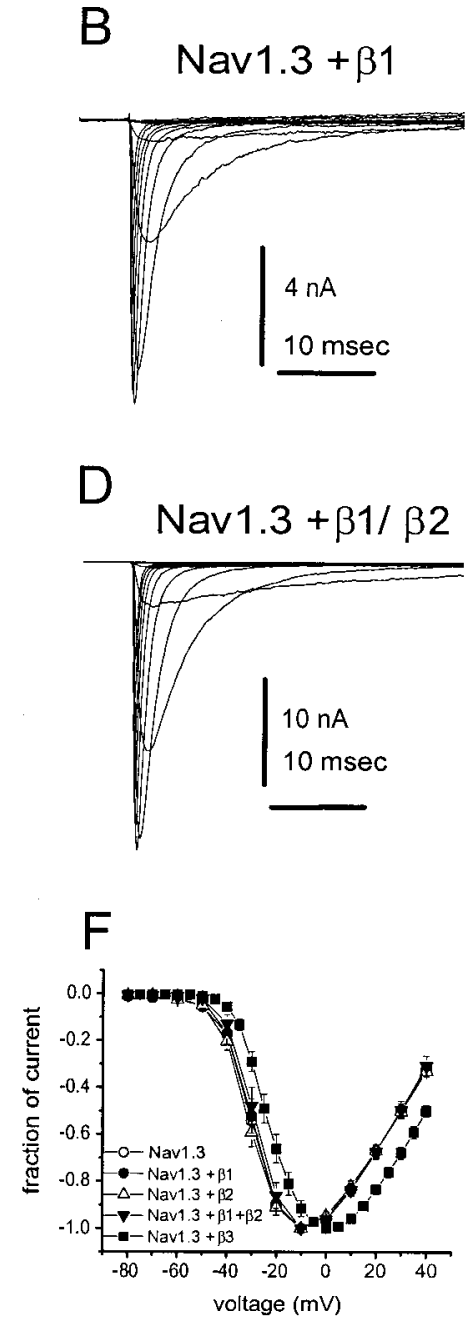

Figure 5. Coexpression of $\beta 3$ subunit alters Nav1.3 activation. Shown are families of traces from representative HEK 293 cells expressing rat Nav1.3 channels alone $(A)$ and Nav1.3 channels coexpressed with the $\beta 1$ subunit $(B)$, the $\beta 2$ subunit $(C)$, the $\beta 1+\beta 2$ subunits $(D)$, and the $\beta 3$ subunit $(E)$. The currents were elicited by $40 \mathrm{msec}$ test pulses to various potentials from -80 to $+40 \mathrm{mV}$. Cells were held at $-120 \mathrm{mV}$. $F$, Normalized peak current-voltage relationship for Nav1.3 channels (open circles; $n=24$ ) and Nav1.3 channels coexpressed with the $\beta 1$ subunit ( filled circles; $n=15$ ), the $\beta 2$ subunit (open triangles; $n=21$ ), the $\beta 1+\beta 2$ subunits (filled inverted triangles; $n=12$ ), and the $\beta 3$ subunit ( filled squares; $n=14)$. The $\beta 3$ subunit shifted the voltage dependence of activation by $>5 \mathrm{mV}$ in the depolarizing direction.

expressed in HEK 293 cells. However, because our goal was to assess the effects of expression of recombinant Nav1.3 channels in HEK 293 cells versus DRG neurons, we felt that the mutant Nav1.3-TTX-R channels would be useful nevertheless because they permitted us to compare expression in the two cell types.

To minimize the possible confounding influence of endogenous TTX-R currents in DRG neurons, we used neurons that had been cultured from SNS-null mutant mice in which the slowly inactivating TTX-R SNS (Nav1.8) channels (Akopian et al., 1996; Sangameswaran et al., 1996) that are rapidly repriming (Elliott and Elliott, 1993) are not expressed (Akopian et al., 1999; Cummins et al., 1999). After several days in culture SNS-null neurons express very small TTX-R persistent currents $(0.33 \pm 0.6 \mathrm{nA} ; n=$ $10)$. We were unable to transfect DRG neurons with the standard calcium phosphate technique. Therefore, biolistic techniques
A

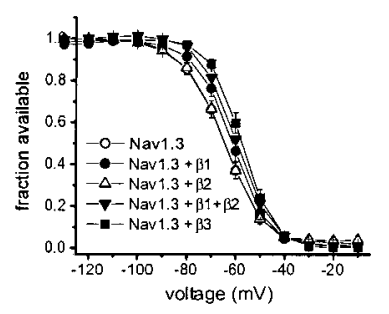

C

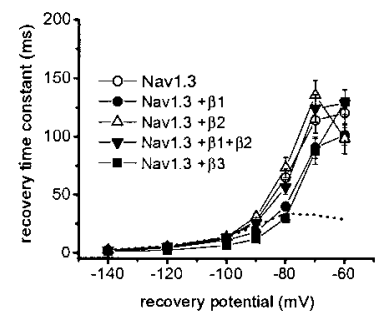

B

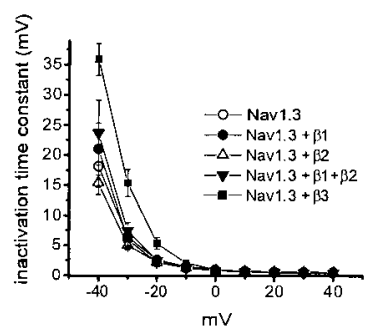

D

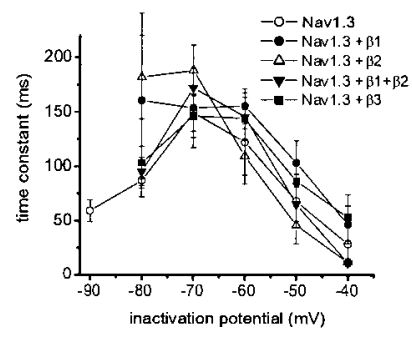

Figure 6. Coexpression of $\beta$-subunits has small effects on the inactivation properties of Nav1.3 currents. Nav1.3 channels were expressed in HEK 293 cells alone (open circles; $n=21$ ) or coexpressed with the $\beta 1$ subunit ( filled circles; $n=16$ ), the $\beta 2$ subunit (open triangles; $n=21$ ), the $\beta 1+\beta 2$ subunits (filled inverted triangles; $n=13$ ), and the $\beta 3$ subunit (filled squares; $n=15$ ). $A$, Comparison of steady-state inactivation for Nav1.3 expressed alone or coexpressed with $\beta$-subunits. Steady-state inactivation was estimated by measuring the peak current amplitude elicited by 20 msec test pulses to $-10 \mathrm{mV}$ after $500 \mathrm{msec}$ prepulses to potentials over the range of -130 to $-10 \mathrm{mV}$. Current is plotted as a fraction of the maximum peak current. $B$, Open-state inactivation kinetics as a function of voltage shown for Nav1.3 expressed alone or coexpressed with $\beta$-subunits. The macroscopic decay time constants were estimated from single exponential fits to the decay phase of currents elicited by $100 \mathrm{msec}$ step depolarizations to the indicated potential. Coexpression of the $\beta 3$ subunit with Nav1.3 slowed macroscopic inactivation at potentials ranging from -40 to $-10 \mathrm{mV}$. $C$, The time constants for recovery from inactivation are plotted as a function of voltage for Nav1.3 expressed alone or coexpressed with $\beta$-subunits. Time constants were estimated from single exponential fits to time courses measured with the protocols shown in Figure $4 C$. Coexpression of the $\beta 1$ subunit and the $\beta 3$ subunit increased the rate of recovery from inactivation for Nav1.3 channels expressed in HEK 293 cells $(p<0.05$ at $-80 \mathrm{mV})$. D, The time constants for development of closed-state inactivation are plotted as a function of voltage for Nav1.3 expressed alone or coexpressed with $\beta$-subunits. Time constants were estimated from single exponential fits to time courses measured with the protocols shown in Figure $2 C$.

(Wellmann et al., 1999) were used to transfect the SNS-null neurons. The SNS-null neurons were shot with GFP alone or with GFP plus Nav1.3-TTX-R plasmid after 3-5 d in vitro, and sodium currents were recorded in the presence of 500 nM TTX 1-2 d after transfection. The input resistance of neurons transfected with GFP plus Nav1.3-TTX-R plasmid $(492 \pm 129 \mathrm{M} \Omega)$ was not significantly different from that of control SNS-null neurons (256 $\pm 46 \mathrm{M} \Omega$ ), and biolistically transfected SNS-null neurons appeared to be morphologically normal (Fig. 7A,B).

Large fast-activating, fast-inactivating sodium currents were observed in HEK 293 cells (Fig. 7C) $(4.1 \pm 0.8 \mathrm{nA}, n=17)$ and SNS-null DRG neurons (Fig. 7D) (24.9 $\pm 7.3 \mathrm{nA}, n=12)$ transfected with the Nav1.3-TTX-R plasmid in the presence of 500 nM TTX, but not in SNS-null neurons transfected with GFP alone (Fig. $7 E)(0.28 \pm 0.1 \mathrm{nA}, n=10)$. The voltage dependence of activation was identical for the two cell types (Fig. $8 A$ ). The 
A

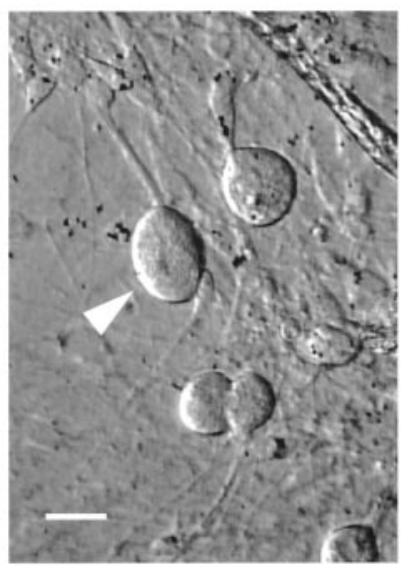

B

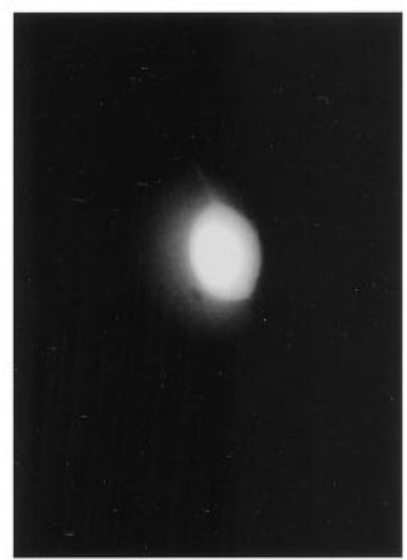

C

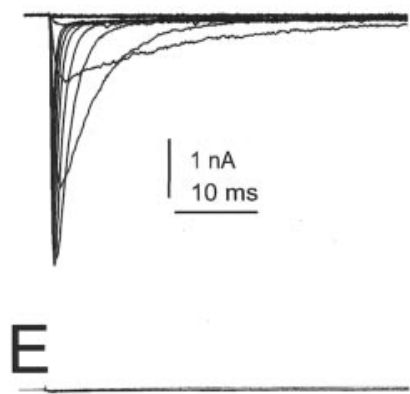

$5 \mathrm{nA}$

$10 \mathrm{msec}$

Figure 7. Transfection of SNS-null neurons and HEK 293 cells with Nav1.3-TTX-R channels. $A$, Photomicrograph of SNS-null neurons after biolistic transfection with GFP plus sodium channel plasmid. Scale bar, 20 $\mu \mathrm{m}$. Many gold particles $(\sim 1 \mu \mathrm{m}$ black particles) are visible throughout the field. Only one of the five neurons in this field was transfected, indicated by the white arrowhead. This neuron exhibited GFP fluorescence $(B)$. $C$, Family of traces from a representative HEK 293 cell expressing rat Nav1.3-TTX-R channels. D, Family of sodium current traces from a representative SNS-null DRG neuron expressing rat Nav1.3-TTX-R channels after biolistic transfection. E, Family of sodium current traces from representative SNS-null DRG neuron after biolistic transfection with GFP alone. For $C-E$, the extracellular solution contained $500 \mathrm{nM}$ TTX to block endogenous TTX-S currents. The currents were elicited by $40 \mathrm{msec}$ test pulses to various potentials from -80 to +40 $\mathrm{mV}$, and the cells were held at $-120 \mathrm{mV}$.

voltage dependence of steady-state fast-inactivation, on the other hand, was $\sim 7 \mathrm{mV}$ more depolarized for Nav1.3-TTX-R channels in SNS-null DRG neurons than in HEK 293 cells (Fig. 8B). The time constants for open-state inactivation (Fig. 8C) were similar for Nav1.3-TTX-R channels in both cell types. The property that showed the greatest difference between cell types was the rate of repriming. The Nav1.3-TTX-R channels reprimed approximately twofold faster at voltages from -100 to $-60 \mathrm{mV}$ when expressed in SNS-null DRG neurons (Fig. 8D), and this difference was statistically significant at -70 and $-60 \mathrm{mV}(p<0.05)$. Thus the recovery from inactivation kinetics of Nav1.3-TTX-R channels seems to be sensitive to the cell background in which it is expressed and is faster in DRG neurons. By contrast, the time constants for the development of closed-state inactivation were similar for Nav1.3-TTX-R channels in both cell types (Fig. 8E). Because Nav1.3-TTX-R channels exhibited slow closed-state inactivation, we predicted that these channels would generate ramp currents. Consistent with this prediction, we found that slow ramp depolarizations can elicit ramp currents in SNS-null DRG neurons transfected with Nav1.3-TTX-R channels (Fig. 8F). However, the voltage dependence of the Nav1.3-TTX-R ramp currents in SNS-null DRG neurons was depolarized compared with the Nav1.3-TTX-R ramp currents recorded in HEK 293 cells (Fig. 8F). The threshold for the Nav1.3-TTX-R ramp currents (defined as the voltage at which the ramp current exceeds $10 \%$ of the peak amplitude) was $12 \mathrm{mV}$ more negative in the HEK 293 cells $(-59 \pm 3 \mathrm{mV}, n=5)$ than in SNS-null DRG neurons $(-47 \pm 5 \mathrm{mV}, n=3)$. Interestingly, this difference in voltage dependence is similar to that observed when we compared Nav1.3 ramp currents in HEK 293 cells with ramp currents recorded from axotomized DRG neurons (Fig. 3D). The ramp currents in axotomized DRG neurons and Nav1.3-TTX-R currents expressed in SNS-null DRG neurons have a similar voltage dependence (Fig. 9).

\section{DISCUSSION}

We have characterized the kinetic and voltage-dependent properties of the currents conducted by rat brain Nav1.3 sodium channels expressed in HEK 293 cells. Although the differences were subtle, the Nav1.3 currents were distinctly different from the currents generated by other TTX-S channels expressed in HEK 293 cells. Because voltage-gated sodium channels can associate with auxiliary $\beta$-subunits, we also examined the consequences of the coexpression of Nav1.3 and the $\beta 1, \beta 2$, and $\beta 3$ subunits. Coexpression of $\beta$-subunits had different effects on Nav1.3 current properties in HEK 293 than have been reported for Nav1.3 currents in Xenopus oocytes. Finally, we have compared the properties of the currents produced by a TTX-R variant of Nav1.3 expressed in HEK 293 cells and DRG sensory neurons. Our data provide insights into how sodium currents in neurons can be regulated by altering the underlying $\alpha$-subunits and $\beta$-subunits that are expressed.

\section{Comparison of Nav1.3 to other Nav isoforms}

Twenty years ago it was not uncommon to refer to the neuronal sodium channel, and it was widely held that voltage-dependent neuronal sodium currents served one primary function, to generate the rising phase of the action potential. It is now known that at least eight different voltage-gated sodium channel $\alpha$-subunits can be expressed in neurons. To what extent these different $\alpha$-subunits have distinct roles in electrogenesis is not entirely clear. However, it is clear that different $\alpha$-subunits can have distinct voltage-dependent and kinetic properties. Two TTX-R sodium channel isoforms have been identified in peripheral neurons. Nav1.8 generates a TTX-R current with macroscopic inactivation in HEK 293 cells that is $\sim 10$-fold slower than the Nav1.3 current (our unpublished observations). Nav1.9 appears to underlie a unique, persistent TTX-R current in small sensory neurons that has very distinct properties compared with other sodium channels (Cummins et al., 1999).

Although the TTX-R neuronal isoforms have very distinctive properties, the TTX-S channels exhibit more subtle differences. Table 1 compares selected properties of Nav1.2, Nav1.3, and Nav1.7 TTX-S neuronal sodium channel $\alpha$-subunits that are expressed and characterized in HEK 293 cells. Although the Nav1.2 
A

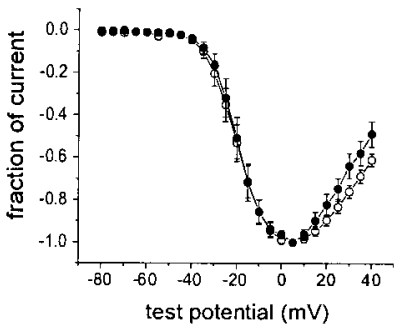

D

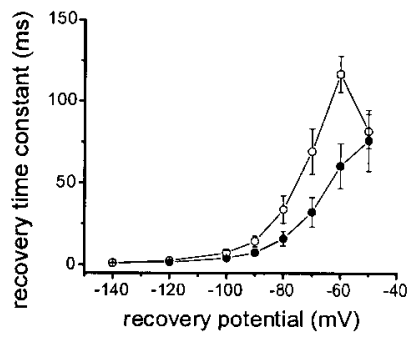

B

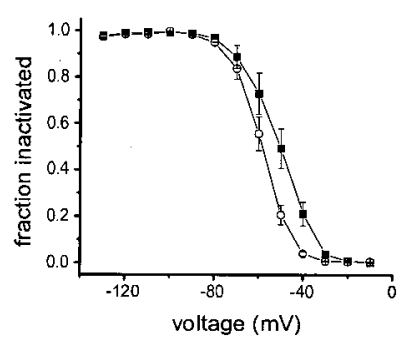

E

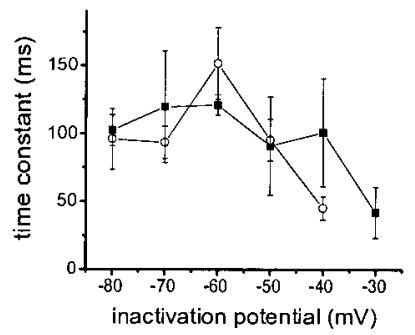

C

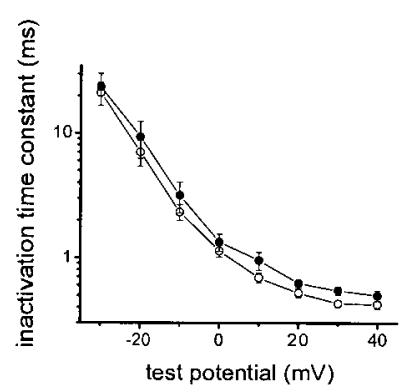

F

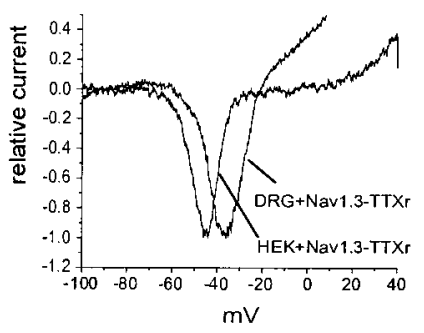

Figure 8. Comparison of Nav1.3TTX-R channels expressed in HEK 293 cells and DRG neurons from SNS-null mice. The Nav1.3-TTX-R channels were expressed in the DRG neurons by using the Helios Gene Gun. The extracellular solution contained $500 \mathrm{~nm}$ TTX to block endogenous TTX-S currents. $A$, Normalized peak current-voltage relationship for Nav1.3-TTX-R channels expressed in HEK 293 cells (open circles; $n=9$ ) and SNS-null DRG neurons ( filled circles; $n=8$ ). The currents were elicited by $40 \mathrm{msec}$ test pulses to various potentials from -80 to $+40 \mathrm{mV}$. Cells were held at $-120 \mathrm{mV}$. $B$, Comparison of steady-state inactivation for Nav1.3TTX-R channels expressed in HEK 293 cells (open circles; $n=9$ ) and SNS-null DRG neurons (filled circles; $n=8$ ). Steady-state inactivation was estimated by measuring the peak current amplitude elicited by $20 \mathrm{msec}$ test pulses to $-10 \mathrm{mV}$ after $500 \mathrm{msec}$ prepulses to potentials over the range of -130 to -10 $\mathrm{mV}$. Current is plotted as a fraction of the maximum peak current. $C$, Openstate inactivation kinetics as a function of voltage. The macroscopic decay time constants are similar for Nav1.3-TTX-R channels expressed in HEK 293 cells (open circles; $n=10$ ) and SNS-null DRG neurons ( filled circles; $n=8$ ). Time constants were estimated from single exponential fits to the decay phase of currents elicited by $100 \mathrm{msec}$ step depolarizations to the indicated potential. $D$, The time constants for recovery from inactivation are plotted as a function of voltage for Nav1.3-TTX-R channels expressed in HEK 293 cells (open circles; $n=10$ ) and SNS-null DRG neurons ( filled circles; $n=$ 9). Time constants were estimated from single exponential fits to time courses measured with the protocol shown in Figure $4 C$. Recovery from inactivation was faster for Nav1.3-TTX-R channels expressed in SNS-null DRG neurons than for Nav1.3-TTX-R channels expressed in HEK 293 cells. $E$, The time constants for development of closed-state inactivation are plotted as a function of voltage for Nav1.3-TTX-R channels expressed in HEK 293 cells (open circles; $n=10$ ) and SNS-null DRG neurons ( filled circles; $n=6$ ). Time constants were estimated from single exponential fits to time courses measured with the protocol shown in Figure 2C. F, Current traces elicited in a representative SNS-null DRG neuron and HEK 293 cell expressing Nav1.3-TTX-R channels by a $600 \mathrm{msec}$ ramp depolarization from -100 to $+40 \mathrm{mV}$. The traces were normalized to compare the voltage dependence of the ramp currents.

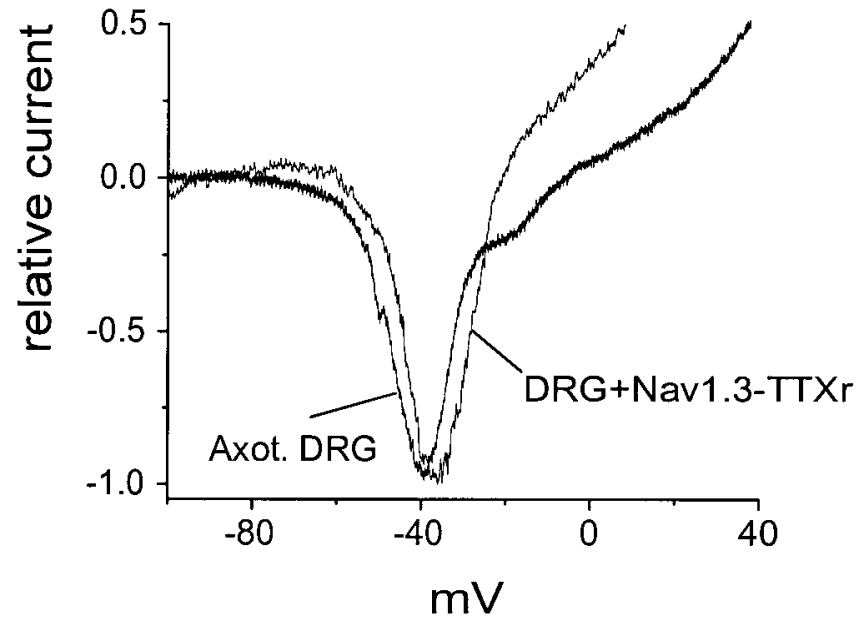

Figure 9. Comparison of ramp currents from an axotomized DRG neuron and a SNS-null neuron after biolistic transfection with Nav1.3TTX-R channels. The current traces were elicited by a $600 \mathrm{msec}$ ramp depolarization from -100 to $+40 \mathrm{mV}$. The traces were normalized to compare the voltage dependence of the ramp currents. So that the Nav1.3-TTX-R ramp current could be recorded, the extracellular solution contained 500 nM TTX to block endogenous TTX-S currents.

currents were characterized in a different laboratory (O'Leary, 1998), we believe that the comparison is valid because both laboratories have characterized the human skeletal muscle (Nav1.4) $\alpha$-subunit (Cummins et al., 1998; O’Leary, 1998) and obtained nearly identical results (see Table 1). Whereas the voltage dependence of activation and steady-state inactivation are slightly more positive for Nav1.2 than for Nav1.3, the voltage dependence of steady-state inactivation is almost $15 \mathrm{mV}$ more negative for Nav1.7 than for Nav1.3. The different isoforms also exhibit substantial differences in the development of, and recovery from, inactivation. The time constant for recovery from inactivation for Nav1.3 channels was intermediate between that for Nav1.2 and Nav1.7. Because repriming kinetics may help to determine how fast a neuron can fire repetitively, this suggests that cells expressing Nav1.3 channels should be able to sustain higher firing rates than cells expressing Nav1.7 channels, but not as high as in cells expressing Nav1.2 channels. Development of inactivation was slower for Nav1.3 and Nav1.7 channels than for Nav1.2 channels. This suggests that cells expressing Nav1.3 and Nav1.7 channels may generate more robust responses to slowly depolarizing inputs than cells expressing Nav1.2 channels, because Nav1.3 and Nav1.7 channels are less likely to undergo closed-state inactivation during slow depolarizations.

\section{Effects of $\boldsymbol{\beta}$-subunit coexpression}

$\beta$-Subunits have been proposed to modulate properties of sodium channel $\alpha$-subunits (Patton et al., 1994; Isom et al., 1995). In Xenopus oocytes, coexpression of the $\beta 1$ subunit with Nav1.3 significantly increases the rate of open-channel inactivation and shifts steady-state inactivation by $-11 \mathrm{mV}$ (Patton et al., 1994). $\beta 1$ has similar effects on the properties of Nav1.1, Nav1.2 (Smith and Goldin, 1998), and Nav1.4 (Nuss et al., 1995) when coexpressed in Xenopus oocytes. However, we found that coexpression of $\beta 1$ with Nav1.3 channels in HEK 293 cells did not have a major effect on open-channel inactivation and, if anything, slightly depolarized the voltage dependence of steady-state inactivation for Nav1.3 


\begin{tabular}{|c|c|c|c|c|c|c|}
\hline \multirow[b]{2}{*}{ Isoform } & \multirow[b]{2}{*}{$\begin{array}{l}\text { Activation } \\
V_{0.5}(\mathrm{mV}) \\
\end{array}$} & \multirow[b]{2}{*}{$\begin{array}{l}\text { Inactivation } \\
V_{0.5}(\mathrm{mV}) \\
\end{array}$} & \multicolumn{2}{|c|}{ Recovery from inactivation } & \multicolumn{2}{|c|}{ Development of inactivation } \\
\hline & & & $\begin{array}{l}\tau \text { at }-100 \mathrm{mV} \\
(\mathrm{msec})\end{array}$ & $\begin{array}{l}\tau \text { at }-80 \mathrm{mV} \\
(\mathrm{msec})\end{array}$ & $\begin{array}{l}\tau \text { at }-70 \mathrm{mV} \\
(\mathrm{msec})\end{array}$ & $\begin{array}{l}\tau \text { at }-60 \mathrm{mV} \\
(\mathrm{msec})\end{array}$ \\
\hline Axotomized TTX-S & -29 & -72 & 14 & 34 & 156 & $112^{a}$ \\
\hline Nav1.3 & -26 & -65 & 11 & 60 & 149 & $122^{a}$ \\
\hline Nav1.2 & -22 & -61 & 8 & 18 & 33 & $52^{b}$ \\
\hline Nav1.7 & -26 & -78 & 26 & 113 & 147 & $92^{c}$ \\
\hline Nav1.4 & $-27 /-28$ & $-72 /-72$ & $5 / 5$ & $16 / 17$ & $28 / 25$ & $20 / 19^{b, c}$ \\
\hline
\end{tabular}

${ }^{a}$ This study.

${ }^{b}$ Cummins et al., 1998.

${ }^{c}$ O'Leary, 1998.

channels (Fig. 6A). $\beta 1$ did increase the rate of recovery from inactivation for Nav1.3 channels, but, overall, $\beta 1$ had only subtle effects on the properties of Nav1.3 currents in HEK 293 cells. $\beta 2$ had no detectable effects on the properties that we examined of Nav1.3 currents in HEK 293 cells. $\beta 3$, on the other hand, had the largest effect on Nav1.3 current properties, shifting the voltage dependence of both activation and steady-state inactivation by 7 $\mathrm{mV}$ in the depolarizing direction, slowing macroscopic openchannel inactivation, and accelerating recovery from inactivation. By contrast, Morgan et al. (2000) reported that $\beta 1$ had larger effects than $\beta 3$ on the properties of Nav1.2a channels expressed in Xenopus oocytes. This difference may reflect differences in the interaction of $\beta$-subunits with specific $\alpha$-subunits. Alternatively, $\beta$-subunits might have different effects on sodium currents in Xenopus oocytes and HEK 293 cells; however, Isom et al. (1995) reported similar effects for $\beta 1$ on the properties of Nav1.2a channels in Xenopus oocytes and Chinese hamster cells. Patton et al. (1994) reported that $\beta 1$ modulates Nav1.3 channels to a smaller extent than Nav1.2a channels in Xenopus oocytes, and their data on $\beta 1$ mRNA expression suggested that $\beta 1$ may not associate with the Nav1.3 sodium channel during development. Although the developmental expression pattern of $\beta 3$ is not known, Shah et al. (2000) recently reported that high levels of mRNA for $\beta 3$ are expressed in small DRG neurons and that chronic constriction injury causes a significant increase in $\beta 3$ mRNA expression.

\section{Comparison of Nav1.3 currents in HEK 293 cells and sodium currents in DRG neurons}

We compared the properties of Nav1.3 sodium currents in HEK 293 cells with the properties of the TTX-S sodium currents in axotomized DRG neurons, which are known (Waxman et al., 1994; Black et al., 1999) to express increased levels (compared with uninjured neurons) of Nav1.3 mRNA and protein. Although there were many similarities, there were some obvious differences. Although the Nav1.3 currents in HEK 293 cells exhibited slow closed-state inactivation like the TTX-S currents in axotomized DRG neurons and large currents were elicited by ramp depolarizations in both situations, the ramp currents generated by Nav1.3 channels in HEK 293 cells activated $\sim 10 \mathrm{mV}$ more negatively than the TTX-S ramp currents recorded from axotomized DRG neurons. Furthermore, although the time constants for repriming were similar at recovery potentials between -140 and $-90 \mathrm{mV}$, repriming was slower for the Nav1.3 currents in HEK 293 cells at more depolarized potentials. In an effort to understand these differences, we expressed a TTX-R variant of
Nav1.3 in cultured DRG neurons and in HEK 293 cells and compared the properties of the TTX-R currents in these cells. Ramp currents generated by Nav1.3-TTX-R channels activated at more negative potentials in the HEK 293 cells than in the DRG neurons, and repriming was faster in the DRG neurons than in the HEK 293 cells. These results indicate that at least some of the differences between Nav1.3 currents in HEK 293 cells and TTX-S currents in DRG neurons are attributable to the cell background, which may produce differences in interactions with $\beta$-subunit or other modulatory proteins.

The rapid repriming that we observed in Nav1.3 channels after expression in DRG neurons suggests that Nav1.3 contributes to the rapidly repriming TTX-S current in axotomized DRG neurons. However, Nav1.3 is not the only contributor to the rapidly repriming TTX-S current in axotomized neurons, because the repriming of Nav1.3-TTX-R currents in DRG neurons was still slower at $-60 \mathrm{mV}$ than for TTX-S currents in axotomized DRG neurons. Although in adult small sensory neurons Nav1.7, which exhibits slow repriming kinetics, is thought to be the predominant TTX-S channel and Nav1.3 expression is increased after peripheral axotomy, these neurons also express detectable levels of Nav1.1 and Nav1.6 mRNA (Black et al., 1996). These distinct isoforms also may contribute to the rapidly repriming TTX-S currents in axotomized DRG neurons.

\section{Conclusions}

Nav1.3 sodium channels are expressed at relatively high levels in the developing nervous system but at lower levels in the mature nervous system. Nav1.3 expression is, however, upregulated in some injured neurons. Our observation, that Nav1.3 channels have different physiological properties when expressed in different cell types, may have methodological implications, especially with respect to the choice of cell type for expression studies. This observation also may reflect at least some degree of cell-specific heterogeneity of channel function within the intact nervous system because many channel types, including Nav1.3, are expressed in many different types of cells. Our data indicate that Nav1.3 channels exhibit distinct properties that may have important implications on cellular excitability. Nav1.3 currents, for example, exhibit slow development of closed-state inactivation and intermediate repriming kinetics and generate large currents in response to slow ramp depolarizations. Our results suggest that Nav1.3 channels contribute to the accelerated repriming of TTX-S sodium currents that is seen in axotomized DRG neurons. The distinct functional properties of Nav1.3 may be important for 
developing neurons and also may contribute to aberrant activity in injured neurons.

\section{REFERENCES}

Akopian AN, Sivilotti L, Wood JN (1996) A tetrodotoxin-resistant voltage-gated sodium channel expressed by sensory neurons. Nature 379:257-262.

Akopian AN, Souslova V, England S, Okuse K, Ogata N, Ure J, Smith A, Kerr BJ, McMahon SB, Boyce S, Hill R, Stanfa LC, Dickenson AH, Wood JN (1999) The tetrodotoxin-resistant sodium channel SNS has a specialized function in pain pathways. Nat Neurosci 2:541-548.

Bendahhou S, Cummins TR, Potts JF, Tong J, Agnew WS (1995) Serine-1321-independent regulation of the $\mu 1$ adult skeletal muscle $\mathrm{Na}^{+}$channel by protein kinase C. Proc Natl Acad Sci USA 92:12003-12007.

Black JA, Waxman SG (1996) Sodium channel expression: a dynamic process in neurons and non-neuronal cells. Dev Neurosci 18:139-152.

Black JA, Dib-Hajj S, McNabola K, Jeste S, Rizzo MA, Kocsis JD, Waxman SG (1996) Spinal sensory neurons express multiple sodium channel $\alpha$-subunit mRNAs. Mol Brain Res 43:117-132.

Black JA, Cummins TR, Plumpton C, Chen YH, Hormuzdiar W, Clare JJ, Waxman SG (1999) Upregulation of a silent sodium channel after peripheral, but not central, nerve injury in DRG neurons. J Neurophysiol 82:2776-2785.

Chahine M, George AL, Zhou M, Ji S, Sun W, Barchi RL, Horn R (1994) Sodium channel mutations in paramyotonia congenita uncouple inactivation from activation. Neuron 12:281-294.

Cummins TR, Waxman SG (1997) Downregulation of TTX-resistant sodium currents and upregulation of a rapidly repriming TTX-sensitive sodium current in small spinal sensory neurons after nerve injury. J Neurosci 17:3503-3514.

Cummins TR, Howe JR, Waxman SG (1998) Slow closed-state inactivation underlies tetrodotoxin-sensitive ramp currents in HEK 293 cells expressing hNE sodium channels and in dorsal root ganglion neurons. J Neurosci 18:9607-9619.

Cummins TR, Dib-Hajj SD, Black JA, Akopian AN, Wood JN, Waxman SG (1999) A novel persistent tetrodotoxin-resistant sodium current in small primary sensory neurons. J Neurosci 19:RC43.

Dib-Hajj SD, Black JA, Felts P, Waxman SG (1996) Down-regulation of transcripts for Na channel $\alpha$-SNS in spinal sensory neurons following axotomy. Proc Natl Acad Sci USA 93:14950-14954.

Dib-Hajj SD, Ishikawa K, Cummins TR, Waxman SG (1997) Insertion of a SNS-specific tetrapeptide in S3-S4 linker of D4 accelerates recovery from inactivation of skeletal muscle voltage-gated $\mathrm{Na}$ channel $\mu-1$ in HEK 293 cells. FEBS Lett 416:11-14.

Elliott AA, Elliott JR (1993) Characterization of TTX-sensitive and TTX-resistant sodium currents in small cells from adult rat dorsal root ganglia. J Physiol (Lond) 463:39-56.

Eubanks J, Srinivasan J, Dinulos MB, Disteche CM, Catterall WA (1997) Structure and chromosomal localization of the $\beta 2$ subunit of the human brain sodium channel. NeuroReport 8:2775-2779.

Felts PA, Yokoyama S, Dib-Hajj S, Black JA, Waxman SG (1997) Sodium channel $\alpha$-subunit mRNAs I, II, III, NaG, Na6, and hNE (PN1): different expression patterns in developing rat nervous system. Brain Res Mol Brain Res 45:71-82.

Gastaldi M, Bartolomei F, Massacrier A, Planells R, Robaglia-Schlupp A, Cau P (1997) Increase in mRNAs encoding neonatal II and III sodium channel $\alpha$-isoforms during kainate-induced seizures in adult rat hippocampus. Brain Res Mol Brain Res 44:179-190.

Goldin AL, Barchi RL, Caldwell JH, Hofmann F, Howe JR, Hunter JC, Kallen RG, Mandel G, Meisler MH, Netter YB, Noda M, Tamkun MM, Waxman SG, Wood JN, Catterall WA (2000) Nomenclature of voltage-gated sodium channels. Neuron 28:365-368.

Horton RM, Ho SN, Pullen JK, Hunt HD, Cai Z, Pease LR (1993) Gene splicing by overlap extension. Methods Enzymol 217:270-279.

Isom LL (2000) Pathology of visceral pain: molecular mechanisms and therapeutic implications. I. Cellular and molecular biology of sodium channel $\beta$-subunits: therapeutic implications for pain? Am J Physiol Gastrointest Liver Physiol 278:G349-G353.

Isom LL, Scheuer T, Brownstein AB, Ragsdale DS, Murphy BJ, Catterall WA (1995) Functional coexpression of the $\beta 1$ and type IIA $\alpha$-subunits of sodium channels in a mammalian cell line. $\mathrm{J}$ Biol Chem 270:3306-3312.

Joho RH, Moorman JR, VanDongen AM, Kirsch GE, Silberberg H, Schuster G, Brown AM (1990) Toxin and kinetic profile of rat brain type III sodium channels expressed in Xenopus oocytes. Brain Res Mol Brain Res 7:105-113.

Kayano T, Noda M, Flockerzi V, Takahashi H, Numa S (1988) Primary structure of rat brain sodium channel III deduced from the cDNA sequence. FEBS Lett 228:187-194.

Klugbauer N, Lacinova L, Flockerzi V, Hofmann F (1995) Structure and functional expression of a new member of the tetrodotoxin-sensitive voltage-activated sodium channel family from human neuroendocrine cells. EMBO J 14:1084-1090.

Morgan K, Stevens EB, Shah B, Cox PJ, Dixon AK, Lee K, Pinnock RD, Hughes J, Richardson PJ, Mizuguchi K, Jackson AP (2000) $\beta 3$ : an additional auxiliary subunit of the voltage-sensitive sodium channel that modulates channel gating with distinct kinetics. Proc Natl Acad Sci USA 97:2308-2313.

Nuss HB, Chiamvimonvat N, Perez-Garcia MT, Tomaselli GF, Marbán E (1995) Functional association of the $\beta 1$ subunit with human cardiac (hH1) and rat skeletal muscle $(\mu 1)$ sodium channel subunits expressed in Xenopus oocytes. J Gen Physiol 106:1171-1191.

O'Leary ME (1998) Characterization of the isoform-specific differences in the gating of neuronal and muscle sodium channels. Can J Physiol Pharmacol 76:1041-1050.

Pan F, Beam KG (1999) The absence of resurgent sodium current in mouse spinal neurons. Brain Res 849:162-168.

Patton DE, Isom LL, Catterall WA, Goldin AL (1994) The adult rat brain $\beta 1$ subunit modifies activation and inactivation gating of multiple sodium channel $\alpha$-subunits. J Biol Chem 269:17649-17655.

Raman IM, Sprunger LK, Meisler MH, Bean BP (1997) Altered subthreshold sodium currents and disrupted firing patterns in Purkinje neurons of Scn8a mutant mice. Neuron 19:881-891.

Sangameswaran L, Delgado SG, Fish LM, Koch BD, Jakeman LB, Stewart GR, Sze P, Hunter JC, Eglen RM, Herman RC (1996) Structure and function of a novel voltage-gated tetrodotoxin-resistant sodium channel specific to sensory neurons. J Biol Chem 271:5953-5956.

Sashihara S, Oh Y, Black JA, Waxman SG (1995) $\mathrm{Na}^{+}$channel $\beta 1$ subunit mRNA expression in developing rat central nervous system. Brain Res Mol Brain Res 34:239-250.

Shah BS, Stevens EB, Gonzalez MI, Bramwell S, Pinnock RD, Lee K, Dixon AK (2000) $\beta 3$, a novel auxiliary subunit for the voltage-gated sodium channel, is expressed preferentially in sensory neurons and is upregulated in the chronic constriction injury model of neuropathic pain. Eur J Neurosci 12:3985-3990.

Smith RD, Goldin AL (1998) Functional analysis of the rat I sodium channel in Xenopus oocytes. J Neurosci 18:811-820.

Tong J, Potts JF, Rochelle JM, Seldin MF, Agnew WS (1993) A single B1 subunit mapped to mouse chromosome 7 may be a common component of $\mathrm{Na}$ channel isoforms from brain, skeletal muscle, and heart. Biochem Biophys Res Commun 195:679-685.

Waxman SG, Kocsis JD, Black JA (1994) Type III sodium channel mRNA is expressed in embryonic but not adult spinal sensory neurons, and is reexpressed following axotomy. J Neurophysiol 72:466-470.

Wellmann H, Kaltschmidt B, Kaltschmidt C (1999) Optimized protocol for biolistic transfection of brain slices and dissociated cultured neurons with a hand-held gene gun. J Neurosci Methods 92:55-64.

Yang N, Ji S, Zhou M, Ptacek LJ, Barchi RL, Horn R, George AL (1994) Sodium channel mutations in paramyotonia congenita exhibit similar biophysical phenotypes in vitro. Proc Natl Acad Sci USA 91:1278512789. 